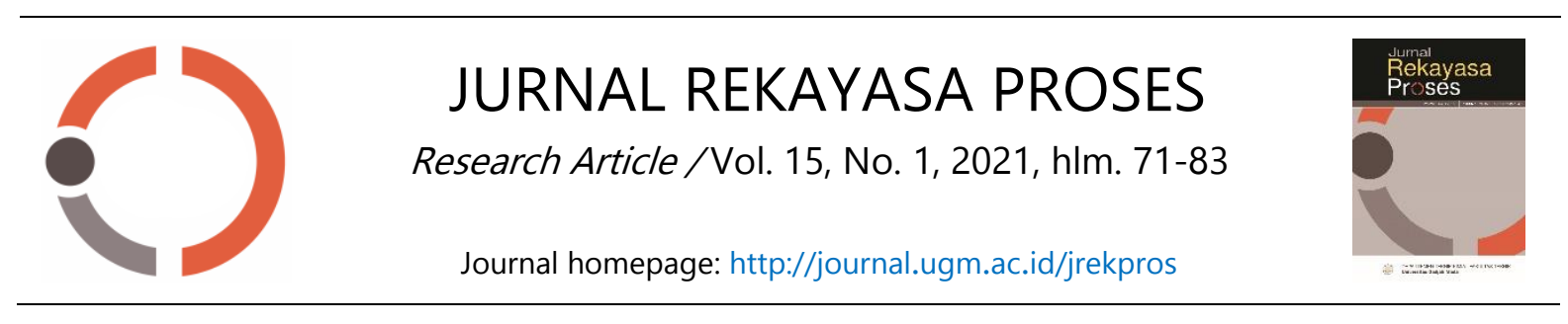

\title{
Evaluasi Aspek Teknis dan Lingkungan Instalasi Pengolahan Air Limbah (IPAL) Komunal di Kabupaten Sleman Yogyakarta
}

\author{
Dwi Saputri ${ }^{1}$, Fajar Marendra ${ }^{2}$, Ahmad Tawfiequrrahman Yuliansyah ${ }^{2,3}$, Agus Prasetya ${ }^{2,3^{*}}$ \\ ${ }^{1}$ Magister Teknologi untuk Pengembangan Berkelanjutan, Program Studi Ilmu Lingkungan, \\ Sekolah Pascasarjana, Universitas Gadjah Mada, Jl. Teknika Utara, Pogung, Mlati, Kampus \\ UGM, Yogyakarta, 55281 \\ ${ }^{2}$ Waste Refinery Center, Fakultas Teknik, Universitas Gadjah Mada \\ JI Grafika No. 2 Kampus UGM, 55281 Yogyakarta \\ ${ }^{3}$ Departemen Teknik Kimia, Fakultas Teknik, Universitas Gadjah Mada \\ JI Grafika No. 2 Kampus UGM, 55281 Yogyakarta, \\ *Alamat korespondensi: aguspras@ugm.ac.id
}

(Submisi: 12 Mei 2021; Revisi: 2 Juni 2021; Penerimaan: 5 Juni 2021)

\section{ABSTRACT}

As the producer of waste (both in solid form and wastewater), the increase of population creates a dominant effect on environmental problems. Escalation of the amount of domestic wastewater has led to greater sanitation problems. Indonesian government has carried out several programs for improving sanitation access and facilities. Community-based wastewater treatment plant (Communal WWTP) is one of the priority programs. Sleman Regency in Special Province of Yogyakarta owns 131 communal WWTP, where the oldest one had been built in 2006 while the newest one was installed in 2018. In this study, the techno-environmental assessment of communal WWTP in the District of Sleman, Yogyakarta was carried out. Sampling selection of communal WWTPs was undertaken using Stratified Random Sampling techniques. Data collection was executed by a combination of field surveys and in depthinterview of several relevant personnel. The study was done for 30 communal WTTP in various Districts in Sleman regency. Assessment was carried out based on the Likert scale of 4. The results showed that the average score for environment aspect was 2.94 (good), while that for technical aspect was 3.52 (very good). Overall, the techno-environmental score of communal WWTP in Sleman Regency, Yogyakarta was 3.23 out of 4, which was categorized as good.

Keywords: communal WWTP; domestic wastewater; Likert scale sanitation; Sleman regency; stratified random sampling

\section{A B S T R A K}

Sebagai produsen limbah (baik limbah padat maupun air limbah), peningkatan jumlah penduduk berpengaruh dominan terhadap masalah lingkungan. Eskalasi jumlah air limbah 
domestik berujung pada masalah sanitasi yang semakin besar. Pemerintah Indonesia sudah menjalankan beberapa program untuk meningkatkan fasilitas dan akses sanitasi. Instalasi pengolahan air limbah komunal (IPAL) menjadi salah satu program prioritas. Kabupaten Sleman memiliki 131 IPAL komunal, yang tertua dibangun tahun 2006 dan yang terbaru pada tahun 2018. Dalam penelitian ini, asesmen teknologi lingkungan (techno-environment) dilakukan terhadap IPAL komunal di Kabupaten Sleman, Yogyakarta. Pengumpulan data dikerjakan menggunakan kombinasi metode survei lapangan dan wawancara mendalam dengan pelaku IPAL komunal yang relevan. Pemilihan sampel IPAL komunal dipilih menggunakan teknik Sampling Acak Terstratifikasi (Stratified Random Sampling). Penelitian dilakukan terhadap 30 IPAL Komunal di berbagai Kecamatan di Kabupaten Sleman. Asesmen dilakukan berdasarkan skala Likert (4). Hasil penelitian menunjukkan bahwa aspek lingkungan memperoleh skor rata-rata 2,94 (baik) dan aspek teknis-teknologis 3,52 (sangat baik). Secara keseluruhan kategori teknologi-lingkungan (techno-environment) dari IPAL Komunal di Kabupaten Sleman Yogyakarta mempunyai skor rata-rata 3,23 dari nilai maksimal 4, dan dikategorikan sebagai baik.

Kata kunci: air limbah domestic; IPAL komunal; Kabupaten Sleman; sanitasi; Sampling Acak Terstratifikasi; skala Likert

\section{Pendahuluan}

Peningkatan jumlah penduduk memberikan efek yang sangat dominan terhadap penurunan daya dukung lingkungan, karena jumlah penduduk memiliki andil besar dalam menghasilkan limbah (Prinajati, 2020). Sayangnya, tidak semua orang memiliki kepedulian terhadap limbah yang mereka hasilkan. Sebagai contoh, di Indonesia baru $67,89 \%$ rumah tangga yang memiliki akses sanitasi layak, artinya masih ada sekitar 80 juta lebih rumah tangga yang langsung membuang air limbahnya ke saluran drainase atau sungai (Prinajati, 2020).

Peningkatan akses sanitasi di kawasan permukiman dilakukan di antaranya melalui program pembangunan Instalasi Pengolahan Air Limbah (IPAL) komunal (Hastuti et al., 2017). Sebagian besar IPAL Komunal dibangun menggunakan kombinasi sistem anaerobik-aerobik. Sistem anaerobik merupakan sistem pengolahan air limbah menggunakan mikroorganisme tanpa menggunakan udara (Tchobanoglous et al., 2003). Sistem ini memiliki beberapa keunggulan di antaranya kebutuhan biaya rendah (Hastuti et al., 2017), berpotensi menghasilkan metana sebagai sumber energi (Liu et al., 2010; Matsuo, 2001)), serta menghasilkan lumpur yang lebih sedikit bila dibandingkan dengan sistem aerobik (Tchobanoglous et al., 2003). Kelemahannya adalah ketidak-tuntasan dalam pemrosesan sehingga air limbah terolah masih belum memenuhi baku mutu. Oleh karena itu, penyempurnaan pengolahan dilakukan dengan proses aerobik yang biasanya dapat berlangsung lebih cepat.

Beberapa daerah di Indonesia memiliki sistem IPAL komunal diantaranya ialah Surabaya (Bhakti dan Herumurti, 2016), Cimahi (Hastuti et al., 2017), Bogor (Prinajati, 2020), Gunung kidul (Hafidh et al., 2016), dan Malang (Pitoyo et al., 2017). IPAL komunal yang berdiri di beberapa daerah di Indonesia dibangun melalui beberapa program di 
antaranya Sanitasi Lingkungan Berbasis Masyarakat (SLBM), Sanitasi Berbasis Masyarakat (Sanimas), Urban Sanitation and Rural Infrastructure (USRI), Dana Alokasi Khusus (DAK), dan Program Nasional Pemberdayaan Masyarakat (PNPM).

Kabupaten Sleman pada saat studi ini dilakukan memiliki 131 IPAL komunal, di mana yang paling tua dibangun tahun 2006 dan yang terbaru dibangun tahun 2018. Sebagai infrastruktur yang dibangun melalui program pemerintah dan selanjutnya dikelola oleh masyarakat, seiring dengan waktu banyak dijumpai permasalahan terhadap IPAL tersebut, yang luput dari pemantauan pemerintah. Di Provinsi DIY, pemantauan oleh instansi terkait dilakukan saat awal beroperasi terhadap 41 IPAL komunal dari 376 IPAL yang ada di seluruh propinsi (Wijayaningrat, 2018). Dari 41 IPAL komunal yang terpantau itu, 11 di antaranya berada di Kabupaten Sleman. Oleh karena itu, terdapat dugaan bahwa banyak IPAL komunal yang terbangun menjadi terbengkalai atau tidak berjalan maksimal karena berbagai sebab, misalnya kesalahan pembangunan, pengoperasian maupun pemeliharaan (Bhakti dan Herumurti, 2016). Atas dasar hal tersebut, penelitian terkait kondisi dan kinerja IPAL komunal perlu dilakukan.

Penelitian terhadap IPAL Komunal telah banyak dilakukan, di antaranya terkait dengan penggunaan Anaerobic Baffle Reactor (ABR) untuk pengolahan limbah organik yang menghasilkan gas metana (Hahn dan Figueroa, 2015), evaluasi dampak lingkungan dari pengolahan limbah domestik (Lam et al., 2015; Li et al., 2013; Lim dan Park, 2009), efisiensi kerja IPAL (Ngoma et al., 2020), maupun evaluasi teknis dan teknologi (Renuka et al., 2016). Namun belum banyak dilakukan penelitian terkait aspek teknislingkungan (techno-environment) pada IPAL komunal di suatu kawasan/wilayah.

Penelitian ini bertujuan untuk melakukan evaluasi tenis dan lingkungan (technoenvironment) terhadap IPAL komunal di Kabupaten Sleman. Evaluasi aspek teknis mengkaji kesesuaian bangunan berdasarkan kriteria teknis, kondisi aktual komponen IPAL, layout IPAL komunal, kapasitas terpasang serta beban air limbah. Evaluasi aspek lingkungan mengkaji kondisi badan air penerima, topografi lahan, lokasi geografis, jenis tanah dimana IPAL berada, serta kualitas effluent IPAL. Skala Likert digunakan untuk mengevaluasi dan memetakan kondisi IPAL secara kuantitatif dan deskriptif-kualitatif, sehingga diharapkan dapat diperoleh gambaran faktual kondisi IPAL komunal di Kabupaten Sleman yang dapat digunakan sebagai landasan pengambilan kebijakan dan program oleh pemerintah dan pemangku kepentingan yang lain.

\section{Metode Penelitian}

\subsection{Data}

Penelitian ini menggunakan data primer dan sekunder. Data primer dikumpulkan dengan observasi langsung dan wawancara di lokasi sampel IPAL. Wawancara mendalam dilakukan dengan responden: pengelola IPAL komunal, pengguna IPAL komunal dan pengurus RT selaku wilayah yang ditempati IPAL. Data sekunder dikumpulkan melalui database pada intansi-instansi terkait serta literatur pendukung lainnya.

\subsection{Metode}

Penelitian ini dilakukan menggunakan metode analisis deskriptif-kualitatif 
(Koentjaraningrat, 1993) dan metode Penelitian dilakukan pada bulan Junikuantitatif dengan melakukan observasi November 2019, dengan mengambil sampel kondisi eksisting IPAL komunal di Kabupaten sebanyak 30 dari 131 IPAL komunal yang ada Sleman. Deskripsi naratif dilakukan sesuai di Kabupaten Sleman, Yogyakarta. Lokasi nilai yang diperoleh dari masing masing IPAL pemilihan sampel ditentukan dengam Komunal yang diteliti. metode Sampling Acak Terstratifikasi

Tabel 1. Kriteria dan indikator aspek teknis dan lingkungan penelitian IPAL komunal

\begin{tabular}{|c|c|c|c|c|c|}
\hline \multirow{2}{*}{ No } & \multirow{2}{*}{ Kriteria } & \multicolumn{4}{|c|}{ Indikator } \\
\hline & & 1 & 2 & 3 & 4 \\
\hline \multicolumn{6}{|c|}{ Aspek Teknis } \\
\hline 1 & Desain IPAL & $\begin{array}{l}\text { Tidak sesuai dengan } \\
\text { perencanaan }\end{array}$ & $\begin{array}{l}\text { Sesuai dengan } \\
\text { perencanaan namun } \\
\text { banyak kesalahan }\end{array}$ & $\begin{array}{l}\text { Sesuai dengan } \\
\text { perencanaan namun ada } \\
\text { sedikit kesalahan }\end{array}$ & $\begin{array}{l}\text { Sangat sesuai dengan } \\
\text { perencanaan }\end{array}$ \\
\hline 2 & $\begin{array}{l}\text { Komponen } \\
\text { IPAL }\end{array}$ & IPAL tidak berfungsi & $\begin{array}{l}\text { Alat sulit dioperasikan, } \\
\text { komponen sering rusak }\end{array}$ & $\begin{array}{l}\text { Alat mudah } \\
\text { dioperasikan, komponen } \\
\text { sering rusak }\end{array}$ & $\begin{array}{l}\text { Alat mudah } \\
\text { dioperasikan, komponen } \\
\text { berfungsi dengan baik }\end{array}$ \\
\hline 3 & Layout & $\begin{array}{l}\text { Tidak sesuai dengan } \\
\text { perencanaan dan tanpa } \\
\text { penjelasan }\end{array}$ & $\begin{array}{l}\text { Tidak sesuai dengan } \\
\text { perencanaan namun ada } \\
\text { penjelasan }\end{array}$ & $\begin{array}{l}\text { Sesuai dengan } \\
\text { perencanaan namun ada } \\
\text { sedikit perbedaan }\end{array}$ & $\begin{array}{l}\text { Sangat sesuai dengan } \\
\text { perencanaan }\end{array}$ \\
\hline 4 & $\begin{array}{l}\text { Kapasitas } \\
\text { Terpasang }\end{array}$ & $\begin{array}{l}\text { Memenuhi 0-25\% dari } \\
\text { rencana }\end{array}$ & $\begin{array}{l}\text { Memenuhi } 26-50 \% \text { dari } \\
\text { rencana }\end{array}$ & $\begin{array}{l}\text { Memenuhi } 51-75 \% \text { dari } \\
\text { rencana }\end{array}$ & $\begin{array}{l}\text { Memenuhi } 76-100 \% \\
\text { dari rencana }\end{array}$ \\
\hline 5 & $\begin{array}{l}\text { Beban air } \\
\text { limbah }\end{array}$ & $\begin{array}{l}\text { Jumlah pengguna } \\
\text { sangat kurang atau } \\
\text { sangat melebihi dari } \\
\text { kapasitas terpasang }\end{array}$ & $\begin{array}{l}\text { Jumlah pengguna } \\
\text { kurang atau melebihi } \\
\text { dari kapasitas terpasang }\end{array}$ & $\begin{array}{l}\text { Jumlah pengguna selisih } \\
\text { sedikit dari kapasitas } \\
\text { terpasang }\end{array}$ & $\begin{array}{l}\text { Jumlah pengguna sesuai } \\
\text { dengan kapasitas } \\
\text { terpasang }\end{array}$ \\
\hline \multicolumn{6}{|c|}{ Aspek Lingkungan } \\
\hline 1 & $\begin{array}{l}\text { Topografi } \\
\text { lahan }\end{array}$ & $\begin{array}{l}\text { Lahan IPAL letaknya } \\
\text { lebih tinggi dibanding } \\
\text { lahan pengguna }\end{array}$ & $\begin{array}{l}\text { Ada banyak rumah yang } \\
\text { kemiringan lahannnya } \\
\text { tidak mendukung untuk } \\
\text { tersambung ke jaringan } \\
\text { IPAL }\end{array}$ & $\begin{array}{l}\text { Ada beberapa rumah } \\
\text { yang kemiringan } \\
\text { lahannya tidak } \\
\text { mendukung untuk } \\
\text { tersambung ke jaringan } \\
\text { IPAL }\end{array}$ & $\begin{array}{l}\text { Kemiringan lahan sekitar } \\
2 \% \text { dengna letak IPAL } \\
\text { lebih rendah dibanding } \\
\text { letak pendistribusian air } \\
\text { limbah pengguna }\end{array}$ \\
\hline 2 & $\begin{array}{l}\text { Badan air } \\
\text { penerima }\end{array}$ & $\begin{array}{l}\text { Lokasi buangan sangat } \\
\text { mengganggu } \\
\text { masyarakat karena } \\
\text { masyarakat berkaktivitas } \\
\text { di tempat tersebut }\end{array}$ & $\begin{array}{l}\text { Lokasi buangan } \\
\text { mengganggu } \\
\text { massyarkat }\end{array}$ & $\begin{array}{l}\text { Lokasi buangan tidak } \\
\text { mengganggu } \\
\text { masyarakat }\end{array}$ & $\begin{array}{l}\text { Lokasi buangan tidak } \\
\text { mengganggu } \\
\text { masyarakat dan tidak } \\
\text { menyebabkan } \\
\text { kerusakan ekosistem. }\end{array}$ \\
\hline 3 & $\begin{array}{l}\text { Kualitas } \\
\text { effluent }\end{array}$ & $\begin{array}{l}\text { Efluen lebih sering } \\
\text { berbau menyengat, } \\
\text { merusak estetika, } \\
\text { mengganggu ekosistem } \\
\text { di dekatnya }\end{array}$ & $\begin{array}{l}\text { Kualitas efluen kadang } \\
\text { buruk pada waktu } \\
\text { tertentu }\end{array}$ & $\begin{array}{l}\text { Kualitas efluen cukup } \\
\text { baik, tidak pernah } \\
\text { mengganggu ekosistem }\end{array}$ & $\begin{array}{l}\text { Kualitas efluen sangat } \\
\text { baik, dibuktikan dengan } \\
\text { hasil uji baku mutu }\end{array}$ \\
\hline 4 & $\begin{array}{l}\text { Letak } \\
\text { geografis }\end{array}$ & $\begin{array}{l}\text { Lokasi IPAL terlalu dekat } \\
\text { dengan rumah warga, } \\
\text { tidak terjangkau truk } \\
\text { penyedot tinja }\end{array}$ & $\begin{array}{l}\text { Lokasi IPAL terlalu dekat } \\
\text { dengan rumah warga, } \\
\text { sulit terjangkau truk } \\
\text { penyedot tinja }\end{array}$ & $\begin{array}{l}\text { Lokasi IPAL memiliki } \\
\text { akses truk tinja, namun } \\
\text { letak IPAL berdekatan } \\
\text { dengan rumah warga }\end{array}$ & $\begin{array}{l}\text { Lokasi IPAL memiliki } \\
\text { akses mudah untuk truk } \\
\text { tinja dan letak IPAL tidak } \\
\text { terlalu berdekatan } \\
\text { dengan rumah warga }\end{array}$ \\
\hline 5 & Bahaya banjir & Lokasi sering banjir & $\begin{array}{l}\text { Lokasi pernah banjir dan } \\
\text { genangan air lama } \\
\text { surut. }\end{array}$ & $\begin{array}{l}\text { Lokasi pernah banjir } \\
\text { tetapi genangan air } \\
\text { cepat surut. }\end{array}$ & Lokasi bebas banjir \\
\hline 6 & Jenis tanah & $\begin{array}{l}\text { Tanah tidak kedap air } \\
\text { atau berpori dan mudah } \\
\text { longsor }\end{array}$ & $\begin{array}{l}\text { Tanah tidak kedap air } \\
\text { atau berpori tetapi tidak } \\
\text { mudah longsor }\end{array}$ & Tanah cukup kedap air & $\begin{array}{l}\text { Tanah kedap air seperti } \\
\text { lempung }\end{array}$ \\
\hline
\end{tabular}


Tabel 2. Kategori penilaian kondisi IPAL komunal

\begin{tabular}{ccccc}
\hline Interval & 1 & 2 & 3 & 4 \\
\hline Nilai & $1,00-1,74$ & $1,75-2,49$ & $2,50-3,24$ & $3,25-4,00$ \\
Kategori & Sangat buruk & Buruk & Baik & Sangat baik \\
\hline
\end{tabular}

Tabel 3. Kelompok zonasi wilayah penilaian dan jumlah IPAL yang diteliti

\begin{tabular}{|c|c|c|c|c|c|}
\hline \multicolumn{5}{|c|}{ Jumlah IPAL } & \multirow{2}{*}{$\begin{array}{c}\text { Jumlah IPAL } \\
\text { yg diteliti }\end{array}$} \\
\hline Zona & Kecamatan & yg diteliti & Zona & Kecamatan & \\
\hline \multirow{4}{*}{1} & Sleman (Sle) & 2 & & Depok (Dep) & 4 \\
\hline & Tempel (Tem) & 2 & 3 & Gamping (Gam) & 4 \\
\hline & Turi (Tur) & 1 & & Mlati (Mla) & 2 \\
\hline & & & & Ngaglik (Nga) & 5 \\
\hline \multirow{4}{*}{2} & Berbah (Ber) & 1 & & Godean (God) & 3 \\
\hline & Kalasan (Kal) & 1 & 4 & Minggir (Min) & 1 \\
\hline & Ngemplak (Nge) & 1 & & Moyudan (Moy) & 2 \\
\hline & & & & Seyegan (Sey) & 1 \\
\hline
\end{tabular}

(Stratified Random Sampling) (Eriyanto, 2007). Pemilihan dilakukan berdasarkan sebaran IPAL Komunal per Kecamatan dan Desa.

Pada setiap sampel IPAL dikenakan perlakuan untuk mendapatkan data yang meliputi dua aspek yaitu aspek teknis dan aspek lingkungan. Dua aspek tersebut dinilai berdasarkan kriteria dan indikatornya, seperti tersaji pada Tabel 1. Kriteria dan indikator ini sangat diperlukan dalam penilaian proyek sanitasi di negara berkembang (Garfi dan Ferrer-Marti, 2011).

Data yang didapatkan kemudian dinilai menggunakan skala Likert yang kemudian diterjemahkan hasilnya secara keseluruhan. Setelah dinilai, data kemudian dikelompokkan menjadi beberapa kategori. Kategori penilaian kondisi IPAL Komunal dalam penelitian ini akan dibagi menjadi 4 seperti pada Tabel 2 (untuk masing-masing Kategori Teknis, Lingkungan dan Keseluruhan).
Hasil penilaian untuk masing-masing kategori teknis dan lingkungan kemudian digambarkan dalam radar-chart. Data dalam radar-chart dikelompokkan dalam 4 (empat) zonasi wilayah, berdasarkan kedekatan kecamatannya secara geografis, seperti tercantum pada Tabel 3.

\section{Hasil dan Pembahasan}

\subsection{Aspek Teknis}

Aspek teknis ini dinilai berdasarkan 5 kriteria yaitu desain IPAL, komponen IPAL, layout, kapasitas terpasang, dan beban air limbah. Capaian nilai pada tiap kriteria tersebut digambarkan dalam radar-chart seperti yang ditunjukkan pada Gambar 1. Aspek teknis dengan nilai tertinggi dimiliki oleh Kecamatan Godean (Zona 4) dan Kecamatan Ngaglik (Zona 3) dengan rerata nilai sebesar 3,80 dengan kategori sangat baik sedangkan nilai terendah ada pada Kecamatan Berbah (Zona 2) dengan nilai 3,20 yang masuk dalam kategori baik. 


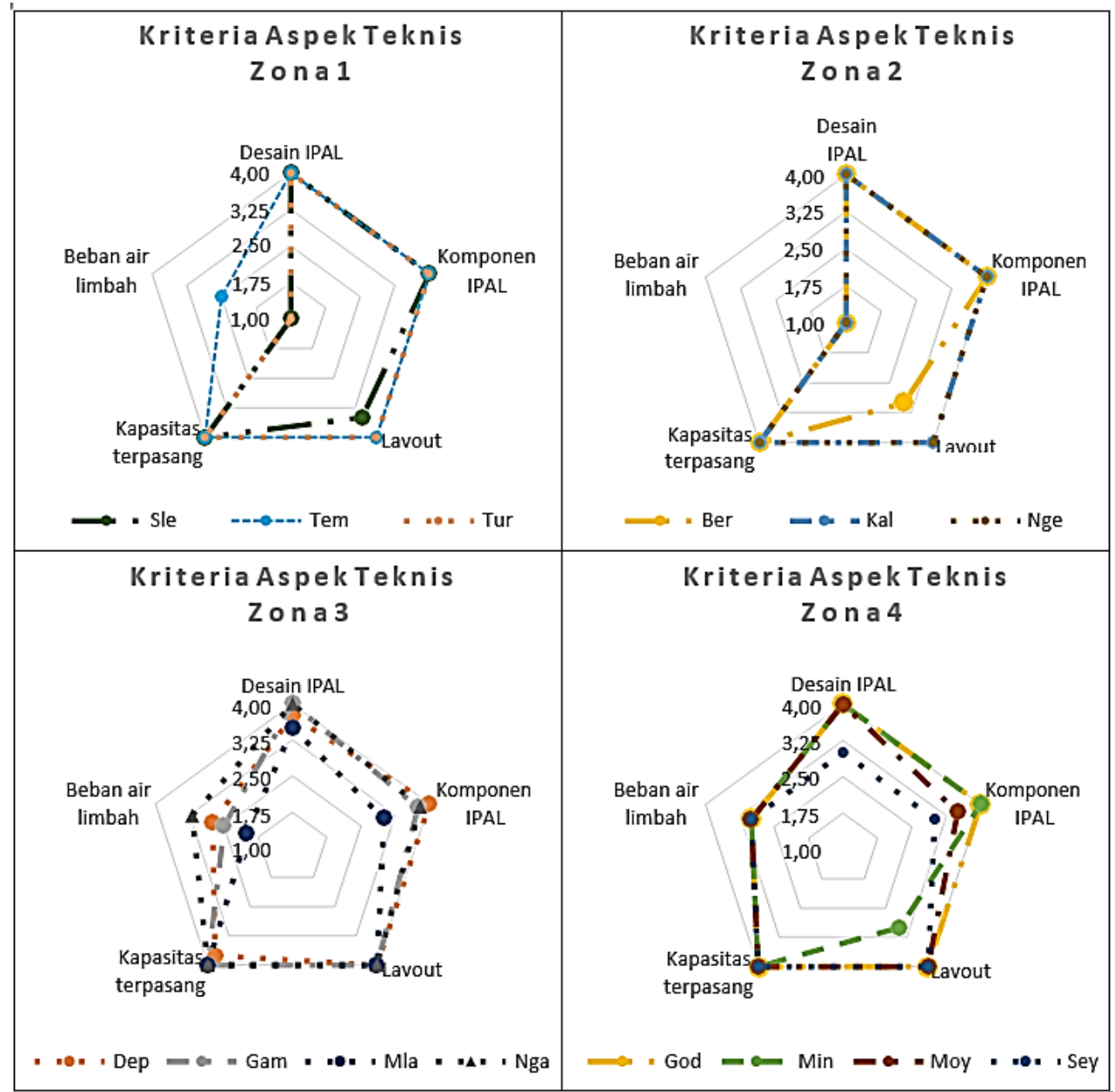

Gambar 1. Radar chart kriteria Aspek Teknis per kecamatan di Kabupaten Sleman

(Keterangan: Sle: Kec. Sleman; Tem: Kec. Tempel; Tur: Kec. Turi; Ber: Kec. Berbah; Kal: Kec. Kalasan; Nge: Kec. Ngemplak; Dep: Kec. Depok; Gam: Kec. Gamping; Mla: Kec. Mlati; Nga: Kec. Ngaglik; God: Kec. Godean; Min: Kec. Minggir; Moy: Kec. Moyudan; Sey: Kec. Seyegan).

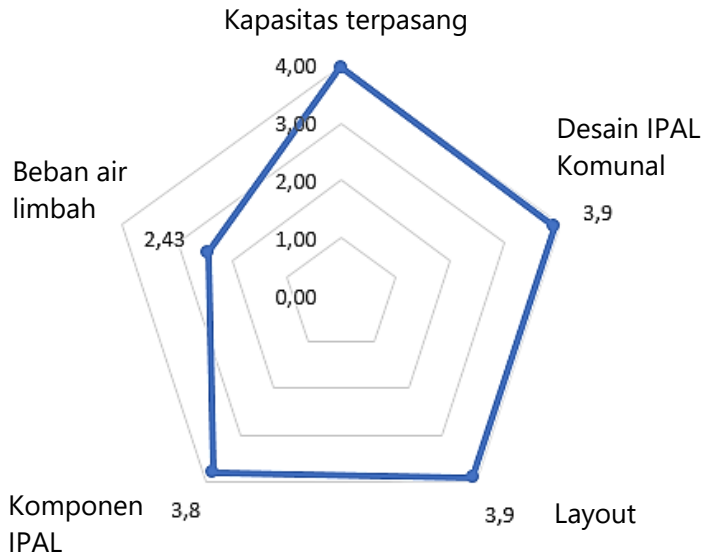

Gambar 2. Radar chart kriteria Aspek Teknis rerata untuk 30 IPAL komunal di Kabupaten Sleman
Gambar 2 menunjukkan radar-chart nilai rerata aspek teknis IPAL Komunal untuk semua kecamatan di Kabupaten Sleman Yogyakarta. Kategori kapasitas terpasang mendapatkan skor terbesar dengan nilai 3,97 (sangat baik). Tempat kedua dicapai oleh aspek desain IPAL Komunal dan aspek layout yang memiliki nilai sama yaitu 3,9 (sangat baik), diikuti oleh aspek komponen IPAL dengan nilai 3,8 (sangat baik). Sedangkan aspek beban air limbah mendapatkan nilai yang paling kecil yaitu pada angka 2,43 (buruk). Hal ini menunjukkan bahwa berdasarkan kapasitas rancangannya, 
desainnya, layout nya serta komponenkomponen IPAL nya, IPAL komunal yang ada dipersepsikan sudah sangat baik/sangat sesuai. Meskipun demikian, beban air limbah yang ditangani IPAL masih dianggap belum sesuai dengan kapasitas.

\subsubsection{Desain IPAL Komunal}

Desain yang digunakan untuk pembangunan IPAL komunal di Kabupaten Sleman yang umum ditemui menggunakan perpaduan teknologi Anaerobic Baffle Reactor (ABR) dan Anaerobic Filter Reactor (AFR). Hal ini sesuai dengan yang dilaporkan oleh Hastuti et al. (2017) bahwa sebagian besar IPAL Komunal yang dibangun pemerintah menggunakan teknologi ABR dan AFR. Filter yang digunakan pada AFR ada 3 macam yaitu filter botol plastik kemasan air mineral, batu vulkanik dan PVC sarang tawon. Jenis filter yang digunakan disesuaikan dengan ketersediaan bahan baku atau supplier pada lokasi pembangunan IPAL. Dimensi ukuran bangunan IPAL komunal juga disesuaikan dengan rencana jumlah pengguna agar daya tampung IPAL sesuai dan kinerja IPAL dapat menjadi efisien.

Seluruh sampel IPAL Komunal mendapatkan score 4, kecuali 2 IPAL di Kecamatan Depok dan 1 di Kecamatan Seyegan (IPAL nomor 2, 3, dan 25 pada Tabel 4). Ketiganya memiliki dimensi ukuran yang jauh lebih kecil daripada rencana awal karena lokasi pembangunan yang tidak memungkinkan, sehingga harus dilakukan penyesuaian ukuran. Meskipun demikian, rerata nilai desain IPAL Komunal ini masih mencapai 3,88 (sangat baik). Desain IPAL Komunal yang dibangun sebelumnya sudah dikonsultasikan pada Tenaga Fasilitator Lapangan (TFL) yang ditunjuk, yang membantu masyarakat dalam membuat Detailed Engineering Design (DED) IPAL. Pada tahap pembangunan IPAL, masyarakat didampingi secara penuh oleh TFL sehingga kecil kemungkinan IPAL yang dibangun menyimpang dari desainnya.

\subsubsection{Komponen IPAL}

IPAL Komunal yang ditemukan di Kabupaten Sleman memiliki komponen dasar yang terdiri dari: jaringan IPAL, sambungan rumah, dan bangunan sentral IPAL Komunal. Jaringan IPAL terdiri dari jalur primer, sekunder, dan tersier. Jalur ini digunakan untuk mendistribusikan limbah dari pengguna ke bangunan sentral IPAL Komunal. Masalah yang sering ditemui pada jalur limbah adalah penumpukan sampah dan masuknya air hujan melalui tutup manhole yang ada di jalanan dan mengakibatkan air limbah meluber pada musim hujan. Pada sambungan rumah pengguna, selalu disediakan grease trap untuk menangkap pasir dan sampah lainnya yang ikut terbawa air limbah. Meskipun demikian, seringkali sampah masih ikut terbawa ke jaringan IPAL akibat jarangnya pengecekan grease trap.

Bangunan sentral IPAL Komunal terdiri dari beberapa komponen, mulai dari inlet, bak penenang, $A B R, A F R$, dan outlet. Pada beberapa IPAL Komunal juga ditemui komponen lainnya seperti rotating biological contactor (RBC), gravel filter, kolam tambahan, wetland, dan atap peneduh. Bangunan Sentral IPAL Komunal pada umumnya berkondisi baik. Meskipun demikian, dijumpai beberapa bangunan yang mengalami keretakan pada dindingnya seperti IPAL di Kecamatan Seyegan dan Mlati.

Komponen IPAL yang sering mengalami masalah dan masyarakat tidak mampu 
memperbaikinya adalah adalah RBC. Perbaikan komponen ini harus dilakukan oleh ahlinya. Dalam kasus di Kabupaten Sleman, perbaikan ini mengandalkan Pusat Teknologi Pengolahan Limbah (Pusteklim) sebagai penyedia teknologi RBC. Kendala lainnya adalah biaya perbaikan RBC jika sudah melewati masa garansi 1 tahun. Biya perbaikan ini dirasakan cukup mahal, sehingga jika Kelompok Swadaya Masyarakat (KSM)/KPP tidak memiliki simpanan dana yang cukup mengakibatkan RBC ini mangkrak. Kasus ini terjadi di KSM/KPP Pelangi Manunggal Warga, Dusun Sukunan, Desa Banyuraden, Kecamatan Gamping.

RBC di IPAL Komunal Tirto Mili, Dusun Jongkang, Desa Sariharjo, Kecamatan Ngaglik bahkan sudah 3 kali mengalami kerusakan dalam kurun waktu 1 tahun. Pada IPAL Komunal Tirto Mili, terdapat dua unit RBC namun yang 1 dalam keadaan rusak. Dengan hanya 1 RBC yang berfungsi, pengolahan air limbah menjadi tidak optimal, mengakibatkan timbulnya bau yang mengganggu.

Nilai kriteria komponen IPAL ini masih tinggi karena kerusakan komponen hanya ada pada beberapa IPAL yang memiliki RBC, sehingga nilai tertinggi mencapai 4 yaitu pada Kecamatan Berbah, Depok, Godean, Kalasan, Minggir, Ngemplak, Sleman, Tempel, dan Turi. Sedangkan nilai terendah masih mencapai angka 3, yaitu pada Kecamatan Mlati, dan Seyegan. Nilai rata-rata untuk aspek komponen IPAL dari semua IPAL yang dipelajari adalah 3,8 (sangat baik).

\subsubsection{Layout}

Layout IPAL Komunal yang dinilai dalam penelitian ini adalah tingkat kesesuaian peletakan komponen IPAL Komunal dengan rencana pembangunannya. Nilai tertinggi yaitu pada Kecamatan Depok, Gamping, Godean, Kalasan, Mlati, Moyudan, Ngaglik, Ngemplak, Seyegan, Tempel, dan Turi yang mencapai angka 4 yang artinya memang sangat sesuai dengan rencana awal tanpa adanya perubahan atau modifikasi sedikitpun. Nilai terendah pada kriteria ini adalah 3, untuk IPAL di Kecamatan Berbah dan Minggir, dikarenakan adanya perubahan realisasi rencana layout. Perubahan yang terjadi pada IPAL di Berbah dan Minggir karena terkendala lokasi yang tidak memadai sehingga perlu pemindahan lokasi IPAL Komunal sentral. Nilai rata-rata untuk aspek layout dari semua IPAL yang dipelajari masih mencapai 3,9 (sangat baik).

\subsubsection{Kapasitas Terpasang}

IPAL Komunal dibangun berdasarkan jumlah kebutuhan masyarakat dalam pengolahan limbah cair domestiknya, sehingga kapasitasnya disesuaikan dengan jumlah penduduk pada tiap lokasi pembangunan. Selain itu, juga harus memperhatikan besarnya biaya pembangunan IPAL yang harus disesuaikan dengan anggaran yang disediakan. Dari 30 IPAL komunal yang dipelajari, kapasitas terpasang terkecil yang ditemui adalah untuk 25 KK (Kepala Keluarga), dan terbesar adalah untuk 100 K. Daftar informasi kapasitas terpakai sampel IPAL Komunal di Kabupaten Sleman tersaji pada Tabel 4.

Dari Tabel 4 di atas terlihat bahwa kapasitas terpasang dari IPAL yang ada lebih besar dari jumlah pengguna, menunjukkan adanya potensi untuk perluasan penggunaan IPAL sesuai dengan perkembangan jumlah warga. Nilai rata-rata untuk aspek kapasitas terpasang masih sangat tinggi, yakni mencapai 3,97 (sangat baik) menandakan 
bahwa kapasitas terpasang memang sangat sesuai dengan perencanaannya.

\subsubsection{Beban Air Limbah}

Nilai Likert untuk beban air limbah diukur berdasarkan kapasitas terpasang dibagi dengan jumlah pengguna atau jumlah rumah tersambung pada konsisi eksisting (saat penelitian dilakukan). Nilai terendah yaitu pada Kecamatan Berbah, Kalasan, Ngemplak, Sleman dan Turi yang hanya mendapatkan nilai 1. Hal ini mengindikasikan bahwa banyak sekali IPAL Komunal yang masih sangat minimal jumlah penggunanya, meskipun memiliki kapasitas terpasang yang besar sesuai dengan rancangan awal. Nilai tertinggi hanya mencapai angka 3,20, yaitu pada Kecamatan Ngaglik. Nilai rata-rata untuk aspek beban air limbah relatif rendah, yaitu 2,43 (buruk).

Tabel 4. Kapasitas terpasang dan jumlah pengguna IPAL komunal

\begin{tabular}{|c|c|c|c|c|}
\hline No & Nama KSP/KPP & Kecamatan & $\begin{array}{l}\text { Kapasitas } \\
\text { Terpasang }\end{array}$ & Jumlah pengguna \\
\hline 1 & Ngudi Saras & Berbah & 100 jiwa & 50 jiwa \\
\hline 2 & Karangayam Sehat & Depok & 300 jiwa & 300 jiwa \\
\hline 3 & Sehat Sejahtera & Depok & 50 SR/600 jiwa & $44 \mathrm{SR}$ \\
\hline 4 & Sumber Sehat & Depok & $100 \mathrm{KK}$ & $28 \mathrm{KK}$ \\
\hline 5 & Guyup Rukun & Depok & $150 \mathrm{KK}$ & $43 \mathrm{SR}$ \\
\hline 6 & Siti Merdiko & Gamping & $500 \mathrm{KK}$ & $400 \mathrm{SR}$ \\
\hline 7 & Pelangi Manunggal Warga & Gamping & $25 \mathrm{KK}$ & $18 \mathrm{SR}$ \\
\hline 8 & Roso Tunggal & Gamping & 400 jiwa & 200 jiwa \\
\hline 9 & Sehat Mulyo & Gamping & 400 jiwa & 70 SR / 300 jiwa \\
\hline 10 & Akur & Godean & $100 \mathrm{SR}$ & $77 \mathrm{SR}$ \\
\hline 11 & Bogo Indah & Godean & $80 \mathrm{KK}$ & $66 \mathrm{KK}$ \\
\hline 12 & Gupit & Godean & $50 \mathrm{KK}$ & $60 \mathrm{KK}$ \\
\hline 13 & Tirta Kencana & Kalasan & 100 KK/400 jiwa & $60 \mathrm{KK}$ \\
\hline 14 & Lestari & Minggir & $100 \mathrm{KK}$ & $60 \mathrm{SR}$ \\
\hline 15 & Sido Dadirejo & Mlati & 400 jiwa & 80 jiwa \\
\hline 16 & Sedyo Mulyo & Mlati & $75 \mathrm{KK}$ & $65 \mathrm{KK}$ \\
\hline 17 & Gondang Asri & Moyudan & 300 jiwa & $49 \mathrm{SR}$ \\
\hline 18 & Agung Manunggal & Moyudan & $200 \mathrm{KK}$ & $72 \mathrm{KK}$ \\
\hline 19 & Mina Sehat & Ngaglik & $100 \mathrm{KK}$ & $68 \mathrm{KK}$ \\
\hline 20 & Wahana Sejahtera & Ngaglik & $100 \mathrm{KK}$ & $90 \mathrm{KK}$ \\
\hline 21 & Tirto Mili & Ngaglik & $400 \mathrm{KK}$ & 384 KK \\
\hline 22 & Gading Indah & Ngaglik & $60 \mathrm{KK}$ & $43 \mathrm{KK}$ \\
\hline 23 & Ngudi Mulyo & Ngaglik & 400 jiwa & $70 \mathrm{KK}$ \\
\hline 24 & Sehat Lestari & Ngemplak & $100 \mathrm{KK}$ & $47 \mathrm{SR}$ \\
\hline 25 & Sembilan & Seyegan & $80 \mathrm{KK}$ & $60 \mathrm{KK}$ \\
\hline 26 & Dukuh Berbakti & Sleman & 400 jiwa & $60 \mathrm{KK}$ \\
\hline 27 & Harapan Asri & Sleman & $100 \mathrm{KK}$ & $42 \mathrm{KK}$ \\
\hline 28 & Ben Sehat & Tempel & $60 \mathrm{KK}$ & $130 \mathrm{SR}$ \\
\hline 29 & Senang Sehat Selalu & Tempel & 500 jiwa & $73 \mathrm{KK}$ \\
\hline 30 & Bangun Sehat Sejati & Turi & 400 jiwa/70 KK & $50 \mathrm{KK}$ \\
\hline
\end{tabular}




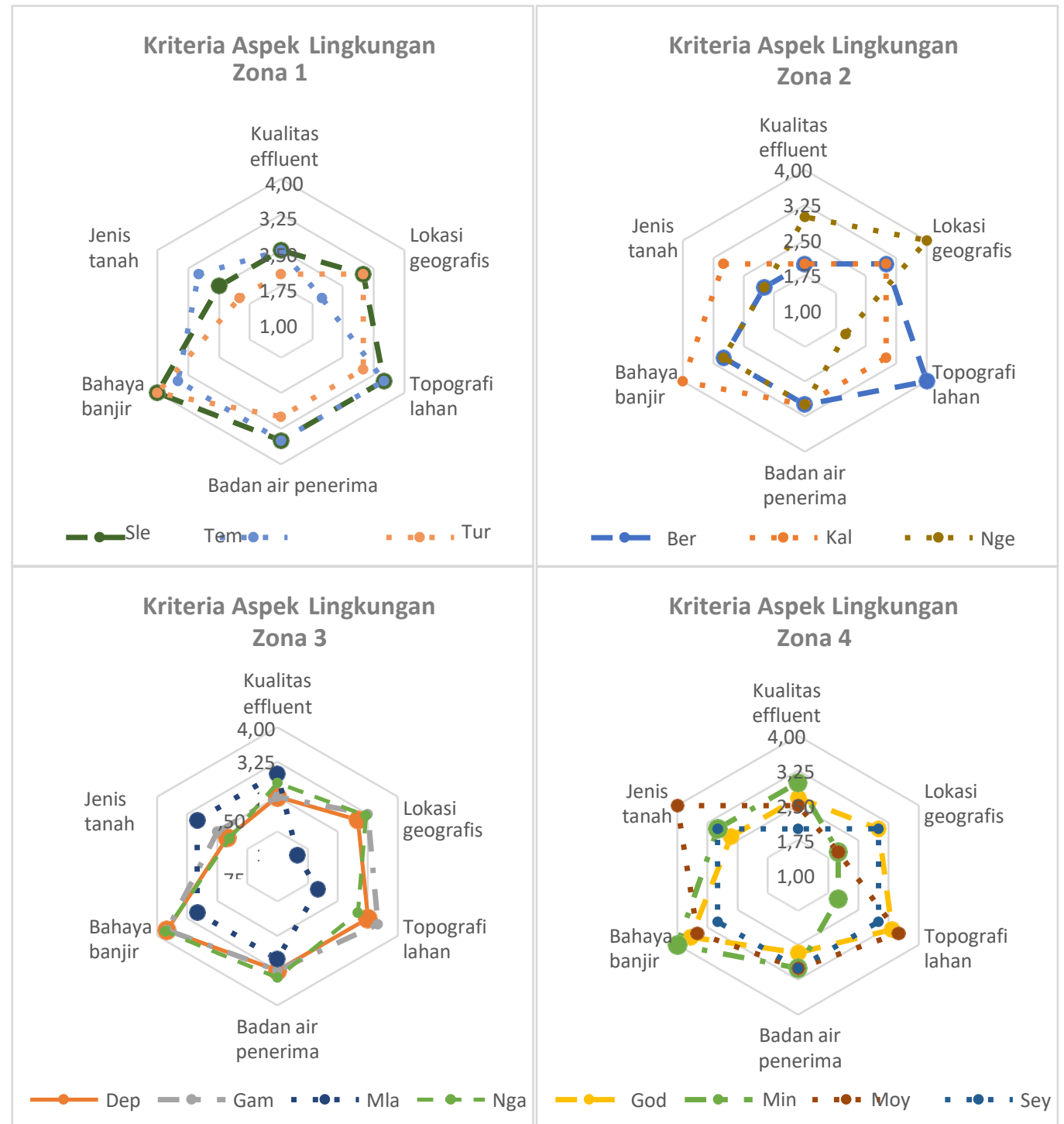

Gambar 3. Radar chart kriteria Aspek Lingkungan per kecamatan di Kabupaten Sleman

(Keterangan: Sle: Kec. Sleman; Tem: Kec. Tempel; Tur: Kec. Turi; Ber: Kec. Berbah; Kal: Kec. Kalasan; Nge: Kec. Ngemplak; Dep: Kec. Depok; Gam: Kec. Gamping; Mla: Kec. Mlati; Nga: Kec. Ngaglik; God: Kec. Godean; Min: Kec. Minggir; Moy: Kec. Moyudan; Sey: Kec. Seyegan).

Temuan ini setidaknya mengindikasikan bahwa tidak semua warga menyalurkan limbahnya untuk diolah di IPAL, dengan berbagai alasan atau penyebab, dan akibatnya kapasitas IPAL yang meskipun dibangun sesuai dengan rencana, pada prakteknya belum termanfaatkan dengan optimal.

\subsection{Aspek Lingkungan}

Aspek lingkungan dibangun berdasarkan beberapa kategori yang digambarkan dalam radar chart pada Gambar 3. Pada skala kecamatan, aspek lingkungan ini tidak ada yang berada di kategori buruk ataupun sangat buruk, namun juga tidak ada yang masuk dalam kategori sangat baik. Kecamatan dengan nilai tertinggi pada aspek lingkungan yaitu Kecamatan Sleman dengan 
nilai 3,17 (baik, dekat dengan batas atas), sedangkan kecamatan dengan nilai terendah yaitu Kecamatan Mlati yang hanya mendapatkan nilai 2,58 (baik, dekat batas bawah).

Rerata aspek bahaya banjir memiliki nilai tertinggi yaitu sebesar 3,63 (sangat baik) diikuti dengan aspek badan air penerima $(3,17$; baik), topografi lahan $(3,13$; baik), lokasi geografis $(2,83$; baik), jenis tanah (2,60; baik) dan aspek kualitas effluent memiliki nilai terendah yaitu sebesar 2,57 (baik). Seperti ditunjukan oleh Gambar 4, secara keseluruhan, rerata yang didapatkan untuk aspek lingkungan IPAL Komunal Kabupaten Sleman adalah 2,94 yang masuk dalam interval 3 dengan kategori baik.

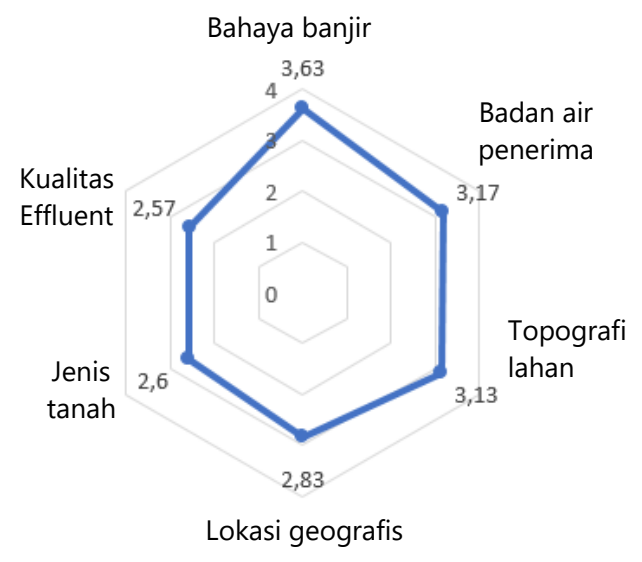

Gambar 4. Radar chart kriteria Aspek Lingkungan rerata untuk 30 IPAL komunal di Kabupaten Sleman

\section{Kesimpulan}

Secara keseluruhan IPAL Komunal di Kabupaten Sleman Yogyakarta memiliki nilai rerata aspek teknis dan lingkungan sebesar 3,23 dari nilai maksimal 4. Nilai ini masuk dalam interval nilai 3 dengan kategori baik. Nilai rerata aspek teknis dan lingkungan memiliki nilai masing-masing sebesar 3,52 (sangat baik) dan 2,94 (baik). Lima aspek teknis IPAL komunal Kabupaten Sleman memiliki nilai sebagai berikut aspek kapasitas terpasang memiliki nilai 3,97 (sangat baik), aspek desain IPAL Komunal dan aspek layout yang memiliki nilai sama yaitu 3,9 (sangat baik), aspek komponen IPAL dengan nilai 3,8 (sangat baik). Sedangkan aspek beban air limbah mendapatkan nilai yang paling kecil yaitu pada angka 2,43 (buruk). Untuk aspek lingkungan, IPAL komunal Kabupaten Sleman memiliki nilai sebagai berikut: Rerata aspek bahaya banjir memiliki nilai tertinggi yaitu sebesar 3,63 (sangat baik) diikuti dengan aspek badan air penerima (3,17; baik), topografi lahan $(3,13$; baik), lokasi geografis (2,83; baik), jenis tanah $(2,6$; baik) dan aspek kualitas effluent memiliki nilai terendah yaitu sebesar 2,57 (baik).

Dapat disimpulkan bahwa secara umum IPAL Komunal di Kabupaten Sleman dalam keadaan baik, baik dari aspek teknis maupun dari aspek lingkungannya. Kapasitas IPAL yang jauh lebih besar dibandingkan dengan beban limbah yang diolah menunjukkan bahwa kebanyakan IPAL komunal yang ada pada saat ini dalam kondisi belum termanfaatkan dengan baik (underutilized). Meskipun kualitas efluen sudah baik, tetapi masih harus ditingkatkan lagi.

\section{Rekomendasi}

Meskipun secara umum IPAL Komunal Sleman dalam dipersepsikan dalam kondisi baik dari aspek teknis dan lingkungan, ada beberapa hal yang harus ditingkatkan. Kelemahan yang paling menonjol adalah kondisi IPAL yang kebanyakan belum termanfaatkan secara optimal sesuai kapasitasnya (under-utilized). Kewenangan untuk hal tersebut berada pada Pemerintah 
Kabupaten Sleman, melalui Dinas yang diberikan otorisasi. Beberapa langkah untuk pengoptimalan pemanfaatan IPAL yang direkomendasikan kepada Pemerintah antara lain: (1). melakukan survei ke wilayah di mana IPAL Komunal masih under-utilized dan memetakan kondisi serta potensi untuk optimalisasinya berdasarkan kondisi geografi wilayah, sebaran rumah dan kesiapan penduduknya, (2). membuat peraturan yang mewajibkan pemilik rumah untuk mengalirkan limbahnya ke IPAL Komunal pada wilayah yang direkomendasikan dari hasil survei, (3). memfasilitasi penambahan jumlah sambungan rumah ke IPAL Komunal, sehingga akan semakin banyak penduduk yang mengalirkan limbahnya ke IPAL.

Hal lain yang perlu ditingkatkan adalah kualitas air buangan (effluent) dari IPAL Komunal. Untuk itu perlu dilakukan: (1) pengontrolan efluen secara berkala, (2). pemeliharaan rutin IPAL Komunal, dan/atau (3). penambahan fasilitas IPAL Komunal, misalnya kolam fitoremediasi atau wetland buatan.

\section{Ucapan Terima Kasih}

Penghargaan yang tinggi penulis sampaikan kepada segenap tim Waste Refinery Center Universitas Gadjah Mada atas bantuan telaah dan diskusi selama penulisan naskah. Ucapan terima kasih juga penulis sampaikan kepada para pengelola IPAL Komunal di Kabupaten Sleman sebagai sumber informasi yang valid.

\section{Daftar Pustaka}

Prinajati, P.D, 2020, Domestic communal wastewater treatment planet evaluation in Sindangrasa, Bogor, Indonesia, Journal of
Community Based Environmental

Engineering and Management, 4(1), 31-36

Hastuti E., Nuraeni, R., Darwati, S., 2017, Pengembangan proses pada sistem anaerobic baffled reactor untuk memenuhi baku mutu air limbah, Jurnal Permukiman, 12(2), 70-79

Tchobanoglous, G, F L Burton, dan H D Stensel, 2003, Wastewater Engineering: Treatment and Use, McGraw Hill, New York.

Liu, Rongrong, Tian, Q, dan Chen, J., 2010, The Developments of anaerobic baffled reactor for wastewater treatment: A review, Afr. J. Biotechnol, 9 (11), 35-42.

Matsuo, T., 2001, Advances in Water and Wastewater Treatment Technology: Molecular Technology, Nutrient Removal, Sludge Reduction and Environmental Health, Elsevier, Amsterdam.

Bhakti, A.H., dan Herumurti W., 2016, Evaluasi kinerja IPAL-IPAL program SPBM-USRI tahun pembangunan 2012-2014 di Surabaya. Jurnal Teknik ITS, 5(2), 23373539.

Hafidh, R., Kartika, F., dan Farahdiba, A. U., 2016, Keberlanjutan instalasi pengolahan air limbah domestic (IPAL) berbasis masyarakat, Gunung Kidul, Yogyakarta, Jurnal Sains dan Teknologi Lingkungan, 8(1), 46-55.

Pitoyo, E., Hendriarianti, E., dan Karnaningroem, N., 2017, Evaluasi IPAL komunal pada Kelurahan Tlogomas, Kecamatan Lowokwaru, Kota Malang. Jurnal Purifikasi, 17(1), 1-10.

Wijayaningrat, A. T. P., 2018, Evaluasi Kinerja IPAL Komunal di Kecamatan Banguntapan dan Bantul, Kabupaten Bantul, D. I. Yogyakarta Ditinjau dari Parameter Fisik Kimia, Tugas Akhir Departemen Teknik 
Lingkungan, Fakultas Teknik Sipil dan Perencanaan, Universitas Islam Indonesia, Yogyakarta.

Hahn, M.J., dan Figueroa, L.A., 2015, Pilot scale application of anaerobic baffled reactor for biologically enhanced primary treatment of raw municipal wastewater, Water Research, 87, 494-502

Lam, L., Kurisu K., Hanaki, K., 2015, Comparative environmental impacts os source-separation systems for domestic wastewater management in rural China, J. Cleaner Prod., 104, 185-198.

Li, Y., Luo, X., Huang X., wang, D., Zhang, W, 2013, Life cycle assessment of municipal wastewater treatment plant: a case study in Suzhou, China, J. Cleaner Prod., 57, 221227.

Lim, S-R., dan Park, J.M., 2009, Environmental impact minimization of a total wastewater treatment network system from a life cycle perspective, J. Environ. Manage., 90, 14541462.

Ngoma, W., Hoko, Z., Misi, S., dan Chidya, R.S.G., 2020, Assessment of decentralized wastewater treatment plant at Mzuzu
University, Mzuzu, Malawi. Phy. Chem. Earth, 118-119, 1-9.

Renuka, R., Mariraj Mohan, S., Sowmiya B., dan Amal Raj, S., 2016, Performance evaluation of panelled anaerobic baffle-cum-filter reactor in treating municipal wastewater, Ecological Engineering, 97, 1-12.

Koentjaraningrat, 1993, Metode-metode Penelitian Masyarakat. PT. Gramedia Pustaka Utama, Jakarta.

Eriyanto, 2007, Teknik Sampling: Analisis Opini Publik, LKIS, Yogyakarta

Garfi, M., dan Ferrer-Marti, L., 2011, Decisionmaking criteria and indicators for water and sanitation projects in developing countries, Water Sci. Technol., 64 (1), 83101. 